\title{
AC 2007-3113: AN UNDERGRADUATE MATERIALS RECRUITMENT AND OUTREACH PROGRAM
}

\section{Lawrence Genalo, Iowa State University}

LAWRENCE J. GENALO is Professor and Assistant Chair of the Department of Materials

Science and Engineering at Iowa State University. He received a Ph. D. in Applied Mathematics with Systems Engineering emphasis in 1977, served as Chair for Freshman Programs and DELOS Divisions, and runs the Toying With TechnologySM Program at Iowa State and the recruitment program in the Materials Science and Engineering Department.

\section{Scott Chumbley, Iowa State University}

L.S. CHUMBLEY Scott Chumbley is a Professor in the Materials Science and Engineering Department at Iowa State University (ISU) and a Scientist at Ames Laboratory, the Department of Energy national laboratory located on the ISU campus. His expertise is in the field of electron microscopy. He has taught the undergraduate Materials Characterization class and graduate level classes on electron microscopy. 


\title{
An Undergraduate Materials Recruitment and Outreach Program
}

\begin{abstract}
An aggressive recruitment strategy, building on previous efforts, began in the Materials Science and Engineering Department at Iowa State University in the late 1990s. Since then the population of undergraduate majors has doubled, as has the percentage of women students, and the average achievement of incoming freshmen (as measured by ACT or SAT scores, high school rank, numbers in the Honors Program, etc.) has also increased dramatically. This recruitment program has its costs; most notably in faculty and staff time. Its cornerstone is a one hour demonstration/presentation (see Appendix for complete listing of demonstrations) that incorporates audience interaction and relates materials properties to real world events (Challenger and Columbia Shuttles, the Titanic, etc.). This presentation is often featured in university and college recruitment events on campus and has been "performed" at K-12 schools and community college events around the state. It has also been given at a distance with the help of the Engineering Distance Education staff. While this is the cornerstone of the recruitment program, it by no means is the only piece. There are numerous efforts integrated in this plan including an innovative, educational, web-based scanning electron microscope that has been used across the globe.
\end{abstract}

This paper will describe the presentation and the supplies needed for it. The paper will also detail the extensive outreach program in the department that has grown during this same period. A scanning electron microscope featuring web access for K-12 partners is a unique feature of this program. K-12 teachers are given training on the use of the microscope and then create lessons that they use in their classrooms with the help of this remote hook-up to the WebSEM. The excellent core of highly involved undergraduate students who have been recruited now form an integral part of the outreach and recruitment efforts. The student Materials Advantage organization has been named outstanding chapter in the country the past three years.

Need

The need for more engineers in the United States, including materials engineers, has been well documented in recent years. "Rising Above The Gathering Storm: Energizing and Employing America for a Brighter Economic Future,"1 a publication from the National Academies, states that "Last year more than 600,000 engineers graduated from institutions of higher education in China. In India, the figure was 350,000. In America, it was about 70,000." The report proposes scholarships to put 25,000 more science and engineering majors into the pipeline each year. Despite a growing, critical need for engineers, "the number of bachelor's degrees awarded in engineering began declining in 1987 and has continued to stay at about the same level through much of the 1990s. The total number of graduates from engineering programs is not expected to increase significantly over the projection period (2000-2010)."2 In the year 2000 an estimated 400,000 engineering jobs were unfilled; projections indicate that number will grow to 1.75 million by $2008 .^{3}$ 
More locally, at Iowa State University in the early to mid 1990s, the number of materials engineering (which at that time consisted of separate ceramic and metallurgical engineering) majors was less than 80 . At a time when university budgets were beginning to see drastic cuts, the department was in danger of being eliminated. A recruitment and retention plan needed to be immediately put in place.

\section{Recruitment and Retention Plan}

It was recognized that the best recruitment strategy was for faculty to spend time with prospective students. The Materials Science and Engineering Department Chair, Dr. Mufit Akinc at the time, appointed the first-named author, Dr. Lawrence J. Genalo, as the recruitment coordinator and allowed for $1 / 4$-time faculty release for this position. The second-named author, Dr. L. Scott Chumbley, in cooperation with other department faculty, had developed a materials presentation aimed at making K-12 students more aware of materials engineering as a possible career path. The presentation includes demonstrations involving audience participation that relate materials information, often about the atomic structure of materials, to real-world events (such as the Titanic, the Challenger, and the Columbia) and current state-of-the-art research projects in the department.
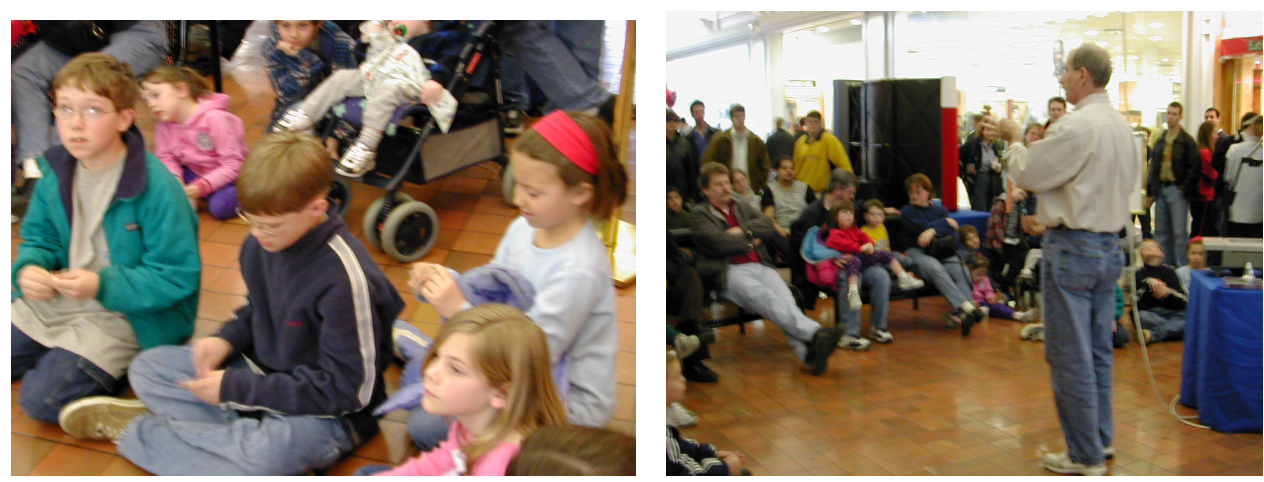

Figures 1A: Engineering Day at the Mall, Kids with Memory Wire Figures 1B: Engineering Day at the Mall, Dr. Genalo Doing Demos

A focused effort was made to develop an aggressive outreach schedule to bring that presentation out to schools and other public venues (for example, the Iowa State Fair). It also is often used when students (in fact, people of all ages) visit Iowa State University. The number of such demonstrations has grown exponentially so that one person can no longer handle the requests. Fortunately the recruitment program has been immensely successful and the resulting student body, who themselves were recruited when they experienced the presentation, are anxious to take part and "perform" the presentation themselves. Today this presentation is often performed by materials engineering undergraduate majors who are part of our student professional organization, The Materials Advantage. This group has been named the outstanding student chapter in the country the past three years.

These materials demonstrations are often presented under the titles of "What's Hot and What's Not" due to the high temperature treatments used to demonstrate tempering steel 
and glass or "Cool Stuff" due to the low temperature (liquid nitrogen) treatments to demonstrate brittle failure. An advertising description such as the following is often used.

Live demonstrations on properties of materials will be performed. The focus is on the atomic structure of the material and how the properties of the material change when the atomic structure is changed. The changes usually are made through the use of extremely hot or cold temperatures. Materials will be set on fire or cooled in liquid nitrogen. They will be broken, shattered, or made stronger. Examples from real-world events such as the Challenger and Columbia Shuttles and the Titanic will be explained.

The complete description of the demonstrations is in the appendix at the end of this paper.
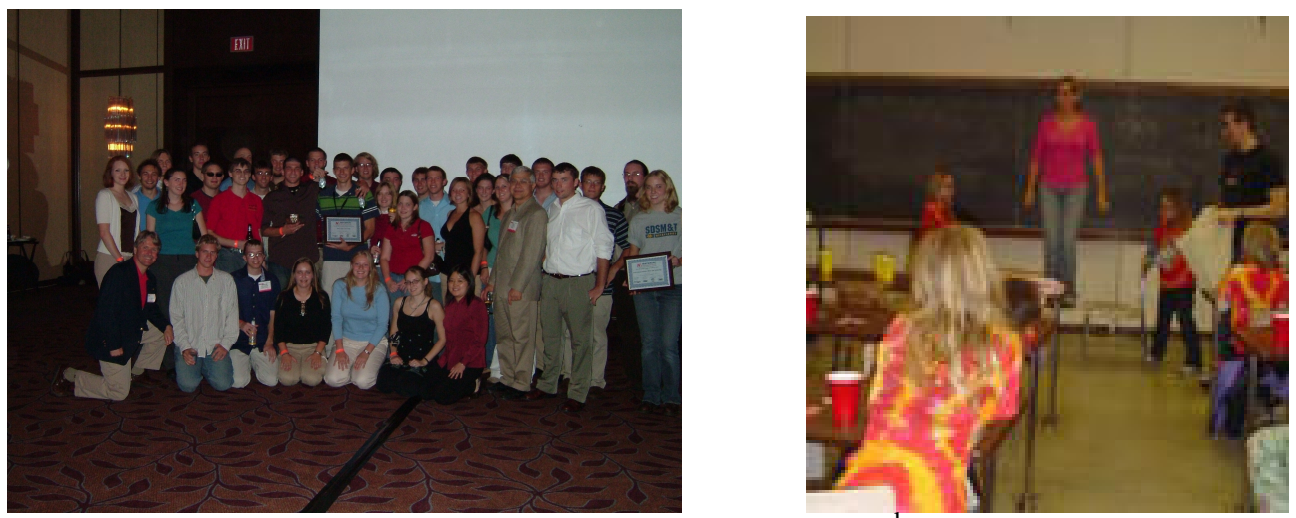

Figure 2A: Materials Advantage Students Receive $3{ }^{\text {rd }}$ Consecutive National Award Figure 2B: Materials Advantage Students Doing Demos

In addition to these demonstrations a number of other activities take place. Materials students serve as hosts and guides for ongoing engineering-wide or university-wide programs. The students volunteer to serve as mentors and role models in events such as the FIRST Lego League robotics competition, Society of Women Engineers events, the Women in Science and Engineering events, and others.
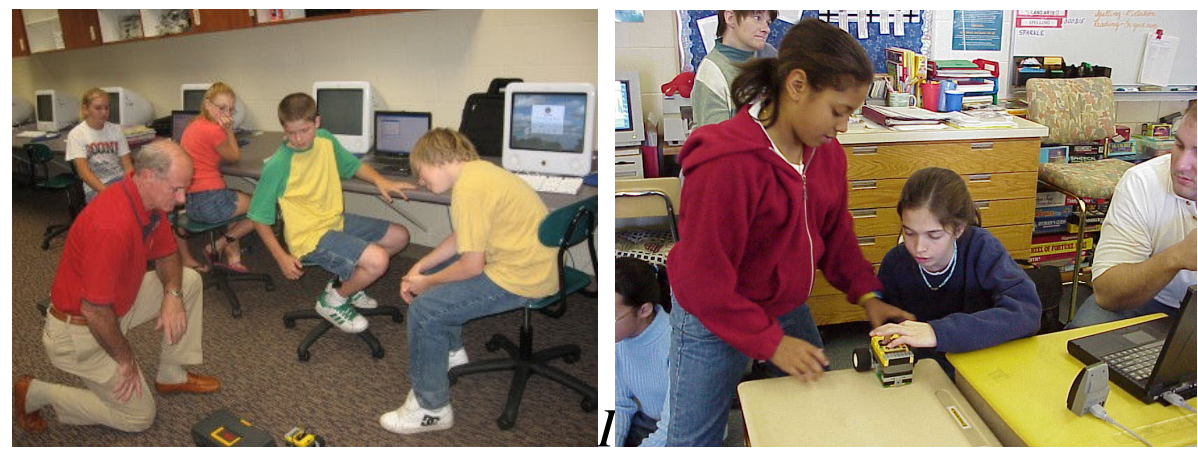

Figures 3A: TWT in Local Classrooms, Dr. Genalo Views a Test Run Figures 3B: TWT in Local Classrooms, Young Engineers at Work

The Toying With Technology ${ }^{\text {SM }}$ (TWT) Program (http://www.eng.iastate.edu/twt), an engineering/teacher education collaborative effort ${ }^{4}$, often interacts with the materials 
department since Dr. Genalo directs that program. Future and current teachers learn about materials, along with other engineering professions, in undergraduate and graduate classes taken by education majors. This program also has a large K-12 outreach program that sees over 200 kids per year.

An innovative portion of the materials recruitment program is the operation of a scanning electron microscope via the web. Project ExCEL ${ }^{5}$ is a program created and run by Dr. Chumbley that provides SEM-based activities for practicing teachers and their K-12 students. It allows teachers to receive training (done each semester and summer in the Toying With Technology ${ }^{\text {SM }}$ Program classes, for example) on the use of the microscope and on possible lessons. It allows them to submit samples and reserve a time for the use of the microscope in their classroom. The only requirement necessary on the part of the participating school is an internet connection. Many of the teachers have provided lessons and feedback to this program, and real-time lessons have been conducted with classrooms as far away as Australia. More information and instructions for scheduling a lesson can be found at http://www.mse.iastate.edu/excel.
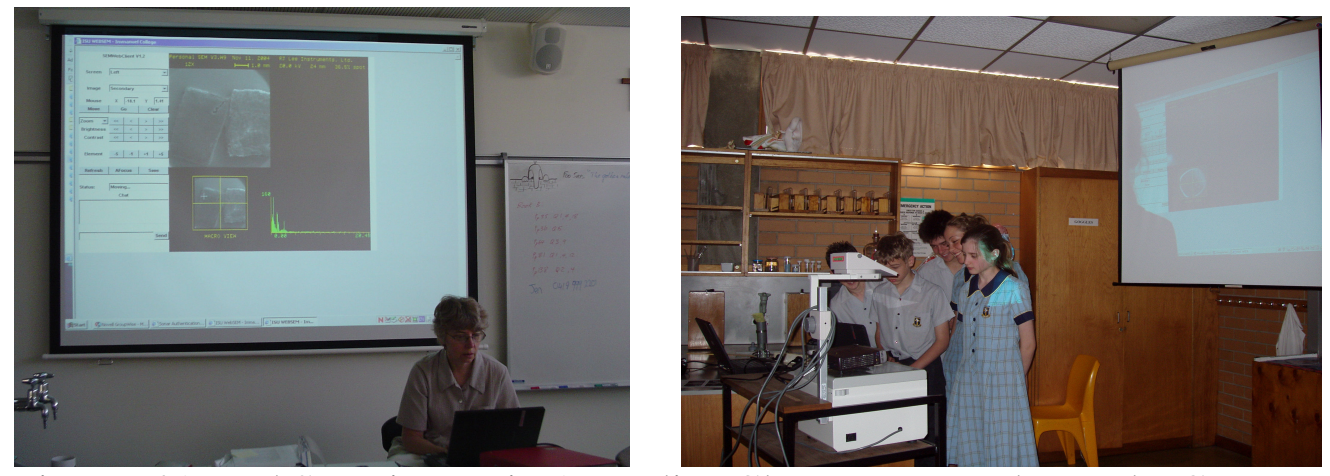

Figures 4A: webSEM in Use in Australian Classroom, Teacher at the Computer Figures 4B: webSEM in Use in Australian Classroom, Students Take a Turn

Results

Figure 5 shows the number of undergraduate students majoring in materials engineering over the past 11 years. It also shows the timeline dates important to the development of the recruitment plan. A slight dip in the enrollment in the 2005-06 school year is seen as a leveling off as the quantity of recruitment efforts off-campus has been decreased. We will monitor the trend to decide if we need to increase those efforts again.

An interesting result of the recruitment has been that the demonstrations, and other recruitment activities, have appealed especially to female students and high achieving students of both sexes. Since 1995 the percentage of women students has gone from less than $20 \%$ to more than $30 \%$. In the same time the number of Honors students has increased to the point where half of the incoming students in the freshmen class are in the Honors Program. The average ACT score for incoming freshmen in materials engineering has recently been about 29; two points higher than the average for the college and 4 points higher than the average for the entire university. The average ACT score before this recruitment program started was at or below the college average. 
Undergraduate enrollment has doubled within the past five years and retention has also increased, primarily as a benefit from recruiting top-notch students in the first place. The students are much more engaged than before. Our Materials Advantage group has over 100 members who participate in outreach activities for recruitment, professional events, social events, research (including co-authoring articles as undergraduates), and national meetings. The group has been named outstanding chapter in the nation in 2004, 2005, and 2006. Having such an engaged student population helps retain new students as they join such an atmosphere. Another added benefit has been that we have more students join our concurrent MS/BS program, thereby increasing our graduate student population. This program is only for students with a 3.5 grade point average or higher (out of 4). Having more highly qualified students has also increased the total number going on to graduate school, whether at ISU or elsewhere, to nearly $50 \%$. Although engineering placement rates have dipped slightly (mid 90s \% from nearly $100 \%$ before 2001), materials engineering placements for ISU students remain at $100 \%$.

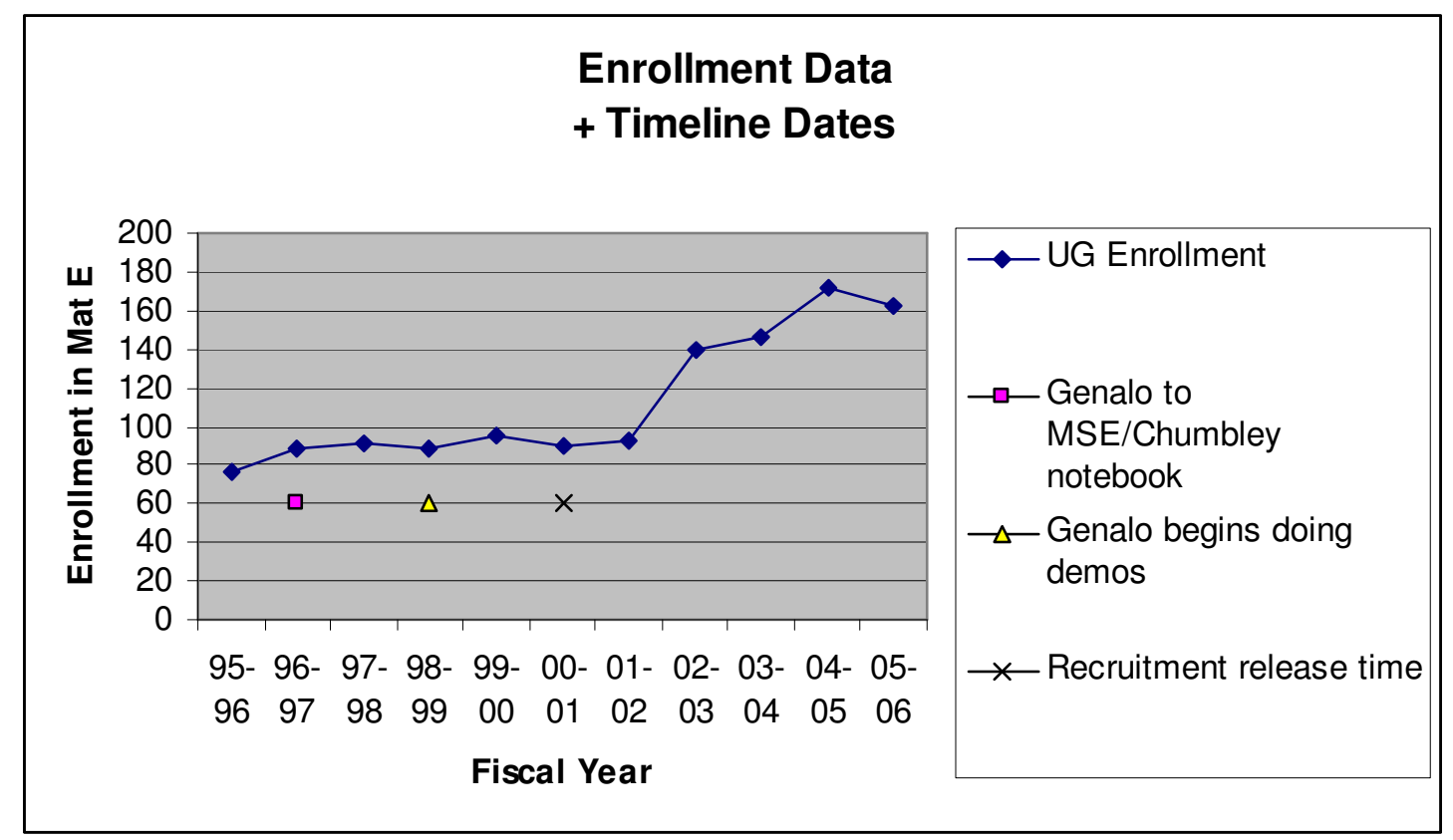

Figure 5: Enrollment Data and Important Dates

Summary

Recruiting is a time-intensive proposition. Faculty must devote time to it as well as staff. Prospective students want to meet the faculty (at least some of them) who they will be learning from and/or working with in research laboratories. The traditional methods of recruitment, often integrating with ongoing college and university-wide efforts, had been done in the past with limited success. The exit interviews with our graduating seniors almost unanimously say that seeing the demonstrations described in this paper is the reason the students become interested in this major.

The materials field is particularly well-suited for success in recruitment efforts for several reasons. First of all, it is not a well-known field among K-12 students so any education, even just the fact that the field exists, will increase the number of students choosing to 
enter the field. Secondly, the science-base and cross-disciplinary nature of the field appeal to students who aren't ready to concentrate on applications they perceive to take them into one field of science at the expense of others. For example students assume, correctly or not, that majoring in chemical engineering means they won't be "doing physics" any more or majoring in mechanical engineering means they will be doing only physics-related applications. Lastly, the fact that atomic structure plays such a vital role in materials work allows for interesting demonstrations that appeal to K-12 students of all ages. Since atoms are first learned about early in elementary school, students can relate to the demonstrations as long as the presenter adjusts the vocabulary of the talk and targets the audience in selecting applications to discuss.

References Cited

1. Rising Above The Gathering Storm: Energizing and Employing America for a Brighter Economic Future, Committee on Prospering in the Global Economy of the 21st Century: An Agenda for American Science and Technology, National Academy of Sciences, National Academy of Engineering, Institute of Medicine, The National Academies Press, 2006.

2. Bureau of Labor Statistics News Release 2000-2010 employment projection.

3. Kapur and Associates, Inc. Newsletter, Volume 8, Issue 2, Spring/Summer 2001.

4. Genalo, L.J. and Ogren, C.E., "K-12 Engineering Education Field Experience," Proceedings of the ASEE Annual Conference, June, 2005.

5. Chumbley, L.S., Constant, K., Hargrave, C.P., and Andre, T., "Project ExCEL - Web-based SEM for K12 Education," Proceedings of the ASEE Annual Conference, June, 2001. 
Appendix

\title{
Materials Science Demonstrations You Can Do!!!!
}

\section{Department of Materials Science and Engineering Iowa State University}

\author{
Scott Chumbley, Kristen Constant \\ 2220 Hoover Hall \\ MSE Department \\ Iowa State University
}

The following list is a series of simple demonstrations that can be done in a high school classroom to illustrate various properties of materials. The demonstrations are loosely divided into five categories: Optical Properties, Magnetic Properties, Chemical Properties, Mechanical Properties, and Thermal Properties. Particular demonstrations may be suitable for chemistry or physics classrooms. However, all are meant to illustrate aspects of the field of materials science. Note that proper safety precautions should be taken when performing these experiments! While some safety matters have been indicated the individual instructor must ultimately decide the proper safety precautions necessary.

Most of the materials listed in these experiments can be obtained cheaply and are usually available locally. Suggested sources and approximate prices are included. Materials that have to be ordered can be obtained from scientific supply companies such as the Edmund Scientific Company, 101 East Gloucester Pike, Barrington, NJ 080071380, phone number (609) 573-6250. This firm offers a free catalog and technical support.

For more information about these experiments, demonstration opportunities offered by the department, or any other technical assistance, feel free to contact the 
Materials Science Department at the above address or you can e-mail us at chumbley@iastate.edu, or constant@iastate.edu. 


\section{OPTICAL PROPERTIES OF MATERIALS \\ Goal of Experiments: \\ To show that light is affected by materials.}

\section{Experiment 1. Calcite Crystal}

\section{Objective:}

To demonstrate birefringence and polarization effects of a transparent material.

\section{Equipment:}

- Calcite crystal (Edmund Scientific, $\approx \$ 4.75$ )

- Two Polarizing sheets (Edmund Scientific, $\approx$ \$20.00)

- Overhead

\section{Background:}

As light passes through calcite the optical properties of the material cause the light to split into two rays, the ordinary and extraordinary rays. These rays are polarized with respect to each other.

\section{Procedure:}

1. Put up an overhead with a small black dot on it or perhaps a single typed letter.

2. Place the calcite on the overhead. Two spots are seen due to the splitting of the light.

3. Rotate the crystal. The dot produced by the extraordinary ray is "fake" i.e. if the calcite crystal is rotated, that spot will move while the real spot remains stationary.

4. Place a Polaroid sheet over the crystal. Rotate the sheet and make each spot disappear.

\section{Experiment 2. Karo Syrup Experiment}

\section{Objective:}

To demonstrate birefringence, dispersion, and polarization effects of a transparent material.

\section{Equipment:}

- Karo syrup (grocery store, $\approx \$ 2.00$ )

- Two polarizing sheets (Edmund Scientific, $\approx \$ 20.00$ )

- Overhead

- Tall graduated cylinder

- Cardboard

\section{Background:}

When light passes through Karo Syrup the optical properties of the sugar molecules cause the light rays to rotate. The amount of rotation depends on the thickness of the syrup layer through which the light passes. 


\section{Procedure:}

1. Place a piece of cardboard on an overhead with a hole cut into it the same diameter as your graduated cylinder.

2. Place a polarized sheet on the cardboard.

3. Place the graduated cylinder over the hole.

4. Have a student hold the second polarized sheet over the top lens of the overhead so no light reaches the screen.

5. Pour the syrup slowly into the cylinder. Different colors of light will be visible as the thickness increases.

6. Have the student rotate the polarized sheet they are holding. Different colors will be seen at different angles.

\section{MAGNETIC PROPERTIES OF MATERIALS Goal of Experiments}

To demonstrate the strength of permanent magnets and cause the student to realize that nonmagnetic materials are still affected by the phenomenon of magnetism.

\section{Experiment 3. Permanent Magnets}

\section{Objectives:}

To illustrate the magnetic properties of Fe-Nd-B permanent magnets and the eddy current response of nonmagnetic conductors to a strong magnetic field. Students should realize that all conductive materials are affected by magnets.

\section{Equipment:}

- Fe-Nd-B permanent magnets of various sizes (Edmund Scientific, $\approx \$ 3.00$ $\$ 300.00$ depending on size and number ordered). Large cow magnets (made of Cobalt-Samarium) also work reasonably well although the effect is reduced. These can be obtained from veterinarians for $\approx \$ 5.00-\$ 10.00$ (or from meat slaughter houses for free).

- Thick (1/4" at least) plates of copper, aluminum, plastic. (Obtain from a metal working shop or salvage yard.)

- Tubes of different materials, e.g., copper, stainless steel, and PVC plastic. (Obtain from a plumber.) Tubes should have an inner diameter slightly larger than the magnet.

\section{Background:}

Fe-Nd-B magnets have the highest energy density of all commercial magnets. They are used in a number of devices used to study materials, as well as in a number of household electronic devices. The phenomenon of eddy currents is used extensively in the area of non-destructive-evaluation to determine whether small cracks invisible to the naked eye are present in metallic structures. 


\section{Procedure:}

1. Stick two magnets to each other through the thickness of your hand or the arm of a younger student and slowly move the magnet up the volunteer's arm as far as it will go. The larger the magnets the greater the thickness of flesh through which the field penetrates. Magnets 1/4" square should stick through the palm of a hand.

2. Flip the bottom magnet over and watch the top one flip by itself.

3. Demonstrate the principle of eddy currents by having students wave a magnet over the surface of the plates as near as possible without scraping the surface. Eddy currents are induced in conductors so you will feel nothing with plastic, very strong eddy currents in $\mathrm{Cu}$ since it is a good conductor, and the $\mathrm{Al}$ will be in between.

4. Place the magnets on the plates and tilt them until the magnet starts to slide. Due to the eddy currents opposing gravity you will have to tilt the $\mathrm{Cu}$ to a high angle before the magnet starts to slide.

5. Drop a small magnet through the $\mathrm{Cu}$ tube. Instead of falling straight through the eddy currents will oppose gravity and it may take 1-3 seconds for the magnet to fall through a tube 18" long. Allow students to look down the tube after you drop the magnet; it almost looks as if the magnet is floating down the length of the tube.

6. Experiment with tubes and plates made from different materials. 


\section{Experiment 4. Superconductivity}

\section{Objective:}

To illustrate the principles of superconductivity and the Meissner effect.

\section{Equipment:}

- Superconductivity kit (Edmund Scientific, \$37.00)

- Liquid nitrogen and dewar (Inquire at welding supply dealers and/or doctor's offices as to the closest source. Liquid nitrogen is cheaper than milk.)

\section{Background:}

A superconductive material carries an electrical current with no loss of electricity due to resistance. Superconductive materials also repel magnetic fields. This is termed the Meissner effect.

\section{Procedure:}

1. Place the superconductor pellet in a petri dish. The petri dish can be insulated somewhat by making a depression in a large piece of styrofoam and placing the petri dish in this depression. (The Edmund Scientific kit may provide a holder.)

2. Pour in liquid nitrogen until the pellet is cold and the LN2 doesn't evaporate immediately.

3. Using plastic tweezers, place a small FeNdB magnet chip (or the magnet provided by Edmund) over the top of the superconductor. The superconductor will exclude the magnetic field and the magnet will remain suspended in thin air over the pellet. 


\section{CHEMICAL PROPERTIES OF MATERIALS \\ Goal of Experiment}

To show that corrosion (commonly called "rust") is a chemical reaction.

\section{Experiment 5. Corrosion and Passivation}

\section{Objective:}

To illustrate the principles of corrosion and passivation of steel.

\section{Equipment:}

- A piece of steel. "Drill rod" which is $\approx 0.9 \% \mathrm{C}$ can be obtained from most metal shops or possibly welding shops.

- Concentrated nitric acid

- Beakers

- Water

- A probe or small chemical spatula

- Tongs

\section{Background:}

All metals oxidize or rust. This is termed corrosion. For many metals the rust layer is so thin it is transparent and so adherent that it protects the metal from further rust. This is the case for aluminum and stainless steel. In some cases the oxide builds up slowly and is only partially protective, such as for silver and copper. In other cases the rust does not protect the metal at all. This is the case for most steels.

\section{Procedure:}

1. PERFORM THIS EXPERIMENT IN A HOOD!

2. Place a small piece of the steel drill rod in a beaker.

3. Pour concentrated nitric acid slowly into the beaker. The strong oxidizing environment of the nitric acid will cause a very adherent oxide or rust to form very quickly and protect the metal from further corrosion.

4. Dilute the acid by pouring water into the beaker. Pour the water in very slowly so as not to disturb the (invisible) oxide layer on the steel.

5. Using the spatula or a probe, scratch the surface of the steel. The scratch will expose unprotected metal to the weak acid and corrosion will begin.

6. Corrosion will be very rapid and will generate a large amount of heat and colored, noxious fumes. Only perform this experiment in a hood!

7. Remove the steel from the diluted acid solution and rinse to stop the reaction. 


\section{MECHANICAL PROPERTIES OF MATERIALS \\ Goal of Experiments}

To show the different mechanical properties of materials and how the strength depends on (1) the atomic state of the material and (2) how a force is applied to a particular design.

\section{Experiment 6. Buckling Breakdown}

\section{Objective:}

To illustrate the principle of "buckling breakdown" where a material is subjected to a stress it was not designed to withstand.

\section{Equipment:}

- A pop can with no dents on the sides at all

- Pencil

\section{Background:}

Soda pop cans are designed to withstand internal pressures. They have a low tolerance to compressive stresses applied perpendicular to the sides, i.e., they dent very easily by applying a few pounds of pressure when squeezing. The strength of the material is such that while the can may dent, it does not puncture. If a compressive stress is applied parallel to the sides, e.g., squeezing the can from the top and bottom, the can is able to withstand almost 160 pounds of force. However, the slightest force perpendicular to the sides will cause the can to collapse.

\section{Procedure:}

1. Place an undented pop can on the floor.

2. Have a volunteer who weighs less than $160 \mathrm{lbs}$ gently step onto the top of the can. Other persons may help the volunteer balance on the can on one foot.

3. Tap the side of the can with the pencil. The can will fail suddenly and crunch flat under the weight of the volunteer.

\section{Experiment 7. Work Hardening}

\section{Objective:}

To illustrate the how metals get harder as you bend them.

\section{Equipment:}

- Copper rod, (or pipe) 1/4 diameter, about 18" long (Obtain from plumber or metal shop)

- Propane torch

\section{Background:}

How easily a metal bends, how hard a metal is, and how far a metal can be stretched before it breaks are all measures of mechanical properties. These properties are directly 
related to the atomic structure of the metal. If a pure metal is heated to a high temperature and cooled it will often be very soft since the atomic structure is very uniform. If the metal is bent the atomic structure will be disturbed and the metal will get much harder.

\section{Procedure:}

1. Clamp the copper rod by one end in a ring stand and using a propane torch (two or three are better) start heating at the far end until the tip is glowing bright red.

2. Slowly move the heat in towards the clamped end so that the red-hot hot zone moves down the length and the entire rod has been heated. It is not necessary to keep the whole rod glowing at the same time; a hot zone 1" or so in width is fine as long as you move it down the whole length.

3. Cool the rod by placing it in a sink full of water or by spraying water over the rod. Be careful not to burn yourself! The bar will now be very soft, so don't bend it! You may want to lightly sand the outside to remove any oxide.

4. Hand the bar to the smallest student in the room and ask them to bend it. They should be able to do this easily. However, it will become very hard due to the bending.

5. Pass the rod to another student and ask them to try and straighten it. They will find this very difficult due to the work hardening effect.

6. This demo can be repeated simply by reheating the $\mathrm{Cu}$, straightening it back out, then reheating again.

7. A coat hanger can also be used for this demo. Bend the straight section of the coat hanger to a "U", then immediately try to bend it back straight. The curve of the "U" will remain bent due to the work hardening effect in this area.

\section{Experiment 8. Glass}

\section{Objective:}

To illustrate the mechanical properties of glass.

\section{Equipment:}

- Pane of tempered glass (Obtain from local glass or window store)

- Two chairs

- Pliers

\section{Background:}

Tempered glass for windows is made by blowing air on the outer surfaces of the glass pane such that they cool very rapidly while the glass in the interior is still warm. When the inside glass cools it shrinks and contracts. This contraction effectively means that the inside glass "pulls" on the outside glass; in engineering terms the outer surfaces are in compression while the inner glass is in tension. The compressive stress gives the glass pane great strength as long as the outer surface is not chipped. If the glass is chipped such that a crack reaches the interior glass that is under tension, the glass pane will shatter as the tensile forces are suddenly released. 


\section{Procedure:}

1. Place the pane flat with the edges supported on two chairs so you have a platform 18" or so off the ground with about 12"-18" of glass unsupported between the chairs. (You may also suspend the pane on $2 " \mathrm{x} 4$ "s placed on the ground.)

2. Slowly stand on the pane such that your entire weight is on the unsupported portion of the glass. The glass should hold up to 400 pounds easily. (N.B. It is extremely rare that the pane will break. If the glass does break it will break in the pane of the glass meaning that glass pieces will fly out parallel to the floor. It is best to have students remain at least 10 feet away and wear safety goggles while doing this demonstration.)

If you wish to demonstrate the effect of a flaw in the glass, the experiment may be continued as follows:

3. Clear everyone from the area. Wear safety glasses. (The pane of glass may be placed in a clear plastic bag if desired.)

4. Support one corner of the pane on one of the chairs or rest it on the floor. Grip the opposite corner with the pliers and squeeze to crack the glass. The pane will shatter, spreading glass over a large area. (Most of the glass will fly in the plane of the pane of glass. Make certain the pane is not pointing toward the class as the glass will fly several feet!) 


\section{Experiment 9. Mechanical Properties Comparison 1}

\section{Objective:}

To illustrate that materials have many common traits.

\section{Equipment:}

- Large steel ball bearing (Obtain from farm implement store or automobile service store)

- $\quad$ Light bulb $(\approx \$ 2.00)$

- $\quad$ racquet ball $(\approx \$ 2.50)$

\section{Background:}

All materials have certain mechanical properties in common. For example, they can all bend a certain amount and still spring back into place. This is called elastic deformation. Polymers (such as rubber or plastics) can bend large amounts. Metals will bend slight amounts before springing back, while ceramics bend only slightly (the bending of the glass pane in the previous experiment is a good example). The elastic properties of materials enable balls to bounce.

\section{Procedure:}

1. Bounce the racquet ball on the floor to illustrate elastic properties.

2. Bounce the metal ball bearing on a hard surface. A thick steel plate or a soap-stone counter top work best but it will bounce on tiled floors and other desk tops (to a much lesser extent).

3. Grip the threaded end of the light bulb gently and release it so that the rounded end of the bulb falls straight down. If the bulb strikes the floor exactly on the end, the bulb will bounce. This works best on a wooden floor. If the bulb tips during the fall to the floor and strikes off center it will break, so be sure students remain some distance away and that safety glasses are worn.

4. The chance of the bulb bouncing without breaking can be improved by etching the surface of the bulb with HF acid to remove any small surface flaws. However, due to the extremely corrosive nature of HF this should only be done by the instructor and with great care!

\section{Experiment 10. Mechanical Properties Comparison 2}

\section{Objective:}

To illustrate that materials behave similarly when under the same relative conditions.

\section{Equipment:}

- Racquet ball, plastic gloves, rubber bands, marshmallows, balloons

- Liquid nitrogen and dewar

\section{Background:}

Ceramics are considered brittle while polymers are thought to be ductile, i.e. they stretch before breaking. Metals are somewhat ductile but not as ductile as polymers. However, 
ceramics melt at high temperatures, metals generally somewhat lower, while polymers melt at a few hundred degrees centigrade. On a relative scale from absolute zero up to the melting point, room temperature is near the top of the scale for polymers while it is near the bottom of the scale for ceramics, so a simple comparison of ductility is not valid. If polymers are cooled to near the bottom of the relative scale (using liquid nitrogen) they are brittle, similar to a ceramic at room temperature. Many metals also get more brittle at low temperatures (see Popular Science February 9, 1995 issue "What Really Sank the Titanic?" discussing the ductile / brittle transition in metals).

\section{Procedure:}

1. Fill the dewar with liquid nitrogen.

2. Using tongs and wearing the proper safety attire, lower various plastic objects into the liquid nitrogen and allow them to cool.

3. Test the ductility of the objects by crushing in your hand, hitting with a hammer, etc.

\section{THERMAL PROPERTIES OF MATERIALS}

Goal of Experiments

To show that temperature effects the structure and properties of materials.

\section{Experiment 11. Memory Metal}

\section{Objective:}

To illustrate the shape-memory effect as a function of temperature.

\section{Equipment: \\ - Memory wire (Obtain from local orthodontist or Edmund's Scientific) \\ - Hot water \\ - Tongs}

\section{Background:}

Nitinol or "memory metal" undergoes a reversible shape change as a function of temperature. The wire is formed into a specific shape at high temperature and then cooled very rapidly. At room temperature the wire can be bend into any shape but once the temperature is raised (to $\approx 95-200^{\circ} \mathrm{F}$ depending on the particular ally) the wire will once again form into the original shape. Orthodontists commonly use memory wire in braces.

\section{Procedure:}

1. Show the students the initial shape of the wire.

2. Deform the wire by straightening it or wrapping it around your finger.

3. Lower the wire into hot water (hot coffee temperature is fine). The wire will return to the original shape. 


\section{Objective:}

To illustrate how the viscosity of glass changes as a function of temperature.

\section{Equipment:}

- Soft soda glass rod (Obtain from chemistry supply store or possibly a window store)

- Torch

\section{Background:}

Although glass is hard and solid it is actually a very viscous liquid. The viscosity is so thick that at room temperature the liquid flow of glass is extremely slow. The "wavy" appearance of very old windows is due to the flow of glass during the manufacturing process resulting in an uneven thickness. Modern window manufacturing methods can maintain a better control over the glass flow and produce windows of uniform thickness. By heating glass to a high temperature the viscosity can be decreased and glass fibers can be formed very easily.

\section{Procedure:}

1. Hold the two ends of the glass rod and heat the center using a laboratory torch. Depending on the length of the rod it may be necessary to wear heat resistant gloves to avoid burns.

2. The glass will become soft and turn yellow in the hot zone of the torch. Demonstrate the lowered viscosity by moving the ends of the glass rod such that the students can see that the hot glass behaves like putty.

3. As the glass becomes soft, pull the two ends apart as you remove the hot zone from the flame, forming a glass fiber.

4. The fiber can be bent a significant amount to demonstrate the elastic properties of the glass.

\section{Experiment 13. Tempered Steel}

\section{Objective:}

To illustrate how heat can be used to "temper" a steel, making it very strong instead of brittle.

\section{Equipment:}

- A piece of drill rod steel, 1/16" in diameter, 18 " long. "Drill rod" which is $\approx 0.9 \%$ $\mathrm{C}$ can be obtained from most metal shops or possibly welding shops. (Very large bobby pins are also suitable for this experiment.)

- Torch

- beaker of water

\section{Background:}

The atomic arrangement of atoms in steel changes with temperature. At room temperature the atoms form a cube with one atom in the center of the cube body (called 
body-centered cubic or BCC) but by heating steel to a high temperature this arrangement can be changed to a cube with atoms on the faces (called face-centered cubic or FCC). If the hot steel is plunged into cold water (called "quenching") the atoms do not have time to go back to the favored BCC arrangement. Instead, a complex structure results which is very brittle. If the steel is reheated slightly the atoms move slightly and the atomic arrangement becomes very hard and tough. This reheating is called tempering and most tool steels have been quenched and tempered.

\section{Procedure:}

1. Cut the rod in half so that you have two pieces, approximately 9" long.

2. Bend the two rods into "U" shapes.

3. Heat the curve of one "U" until it becomes bright orange using the torch. (You can hold the two ends of the " $U$ " in your hand during heating, steel has a very low thermal conductivity so the ends will not get hot.) Immediately plunge the hot section of the rod into a container of cold water. This is called quenching. (Note: If large bobby pins are used they are often coated with a plastic resin coating which will burn off in the flame.)

4. Repeat Step 3 above with the second "U". Once this "U" has been quenched in the water, reheat it slightly in the flame. It is only necessary to get the metal warm, DO NOT get it so hot as to cause the color to change. This is called tempering.

5. Pull the two ends of the two "U"s apart. The steel which was only quenched will be very brittle and will break easily. The quenched and tempered " $U$ " will be so strong and tough in the region of the "U" that it will be impossible to get it to bend in this region. 